ИЗВЕСТИЯ АҚАДЕМИИ НАУК ЭСТОНСКОП ССР. ТОМ 27 Химия. 1978, № 4

\title{
СОСТАВ ИРОНА, СИНТЕЗИРОВАННОГО НА ОСНОВЕ РЕАҚЦИИ ТЕЛОМЕРИЗАЦИИ
}

В работе изучен состав и структура компонентов ирона, который синтезировали из 6-метилгеранилхлорида, полученного реакцией теломеризации.

Компоненты оинтезированного продукта разделяли методом препаративной газовой хроматографии. Полученные индивидуальные компоненты были идентифицированы при помощи масс-спектров и спектров ядерно-магнитного резонанса $\left({ }^{13} \mathrm{C}\right)$. При этом доказано, что во всех пробах имеются $\alpha$-ионон, транс-4-метил- $\alpha$-ионон, транс- $\alpha$-ирон, цис$\alpha$-ирон и $\beta$-ирон, которые составляли от 98,1 до $99,3 \%$ от состава синтетического ирона.

\section{Экспериментальная часть}

Газохроматопрафический анализ ирона проводили на хроматографе Хром-31 с пламенно-ионизационным детектором. Колонка из нержавеющей стали, длиной $4 \mu$ и с внутренним диаметром 4 мм, стационарная фаза: гептафениловый эфир (5\% от веса носителя), твердый носитель: Хроматон- $N-A W(0,25-0,315$ мм) .

Анализ ирона проводили при следующих условиях:

$$
\begin{array}{ll}
\text { температура колонки } & -200^{\circ} \mathrm{C} \\
\text { температура испарителя } & -300^{\circ} \\
\text { давление газа-носителя (Не) на входе }-1,5-1,0 \mathrm{\kappa} / \mathrm{cm}^{2} .
\end{array}
$$

\begin{tabular}{|c|c|c|c|c|}
\hline \multirow{2}{*}{$\begin{array}{c}\text { Порядок } \\
\text { выхода } \\
\text { компо- } \\
\text { нентов } \\
\text { при } \\
\text { анализе }\end{array}$} & \multirow{2}{*}{$\begin{array}{c}\text { Содержание } \\
\text { компонентов } \\
\text { в разных пар- } \\
\text { тиях ирона, \% }\end{array}$} & \multicolumn{2}{|c|}{$\begin{array}{c}\text { Содержание компонентов } \\
\text { ирона после препаратив- } \\
\text { ного разделения, \% }\end{array}$} & \multirow{2}{*}{$\begin{array}{c}\text { Результаты идентификации } \\
\text { компонентов }\end{array}$} \\
\hline & & $\begin{array}{c}\text { Первичная } \\
\text { очистка }\end{array}$ & $\begin{array}{c}\text { Вторичная } \\
\text { очистка }\end{array}$ & \\
\hline
\end{tabular}

Таблица 1

Результаты анализа, препаративного разделения и идентификации компонентов ирона

$1 \quad 1,95-5,06$

2. $\quad 1,98-5,23$

$3 \quad 40,71-55,22$

$4 \quad 30,45-44,66$

$5 \quad 4,64-7,87$

$\begin{array}{cc}85 & 96-98 \\ 80 & 98-99 \\ 95,0-96,0 & - \\ 96,0-97,0 & - \\ 75 & 95-97\end{array}$

a-Ионон

4-Метил-транс- $\alpha$-ионон транс- $\alpha$-Ирон цис- $\alpha-$ Ирон

ק-Крон 
Аналитическая хроматограмма синтетического ирона. $1-\alpha$-ионон, $2-4$-метилтранс- $\alpha$-ионон, 3 - транс- $\alpha$-ирон, 4 цис- $\alpha$-ирон, 5 - $\beta$-ирон. (Остальные компоненты не идентифицированы).

В табл. 1 приведены результаты анализа синтетического ирона, а на рисунке - хроматограмма, иллюстрирующая разделение компонентов.

Препаративное газохроматографическое разделение компонентов синтезированного ирона проводили на хроматографе Хром-31 с пламенно-ионизационным детектором. Колонка длиной 4,5 м и с внутренним диаметром 10 мм, стационарная фаза: гептафениловый эфир (10\% от веса носителя), твердый носитель: Хроматон- $N-A W$ $(0,4-0,63$ мм). Условия препаративного разделения:

$\begin{array}{ll}\text { температура колонки } & -175^{\circ} \\ \text { температура испарителя } & -350^{\circ} \\ \text { давление газа-носителя (Не) на входе }-0,75 \kappa 2 / c \mu^{2} .\end{array}$

Вводимая доза:

1. 200 мкл - для получения компонентов, содержание которых в исходной смеси более $30 \%$ (табл. 1; рисунок).

2. 700 мкл - для получения компонентов, содержание которых в исходной смеси менее $10 \%$ (табл. 1; рисунок). В этом случае для получения веществ предусмотренной чистоты $(>90 \%)$ проводили вторичное хроматопрафирование. Результаты препаративного разделения приведены в табл. 1.

Для идентификации пяти индивидуальных компонентов ирона использовали опектральные методы анализа:

1. При помощи масс-спектров (спекпрометр МХ-1303) было доказано, что лишь выходящий первым из колонки компонент (рисунок; табл. 1) имеет молекулярную массу 192 (13 атомов углерода), а все остальные имеют молекулярную массу 206 (14 атомов углерода).

2. Строение выделенных компонентов легко определяется по их спектрам ЯMP ${ }^{13} \mathrm{C}$. Спектры сняты при частоте $15,1 M \Gamma ц$ на универсальном спектрометре [ $\left.{ }^{1}\right]$. Химические сдвиги измеренных соединений без растворителя приведены в табл. 2.

Первая выделенная фракция $\mathrm{C}_{13} \mathrm{H}_{20} \mathrm{O}$ идентична $\alpha$-ионону, химические сдвиги которого определены также из отдельного образца - смеси $\alpha$ - и $\beta$-ионона. Данные полученных химических сдвигов $\alpha$-ионона незначительно отличаются от опубликованных $\left[{ }^{2}\right]$, за исключением сигнала при 29,0 м. д., который отсутствует в спектре $\alpha$-ионона. На основе химических сдвигов метилциклогексенов [3] и ненасыщенных кетонов [4] следует изменить отнесение некоторых линий $\alpha$-ионона, приведенных в работе $\left[{ }^{2}\right]$. Химические сдвиги $\beta$-ионона в смеси с $\alpha$-иононом незначительно 
отличаются от сдвигов $\beta$-ионона в растворе ацетона [5], если считать химическим сдвигом ГМДС относительно ТМС 1,2 м. ә. [ [6].

Вторая фракция $\mathrm{C}_{14} \mathrm{H}_{22} \mathrm{O}$ является 4-транс-метил- $\alpha$-иононом. Химические сдвиги при 54,$2 ; 131,5 ; 22,9 ; 147,4 ; 134,4 ; 195,6$ и 26,9 близки сдвигам C-1, $2,11,7,8,9,10$ в $\alpha$-иононе, а химический сдвиг оставшегося ненасыщенного углеродного атома указывает на присутствие метильного заместителя у С-4 [ $\left.{ }^{3}\right]$. Равенство химических сдвигов 4-метильной группы в 4-метил- $\alpha$-иононе и транс-3,6-диметилциклогексене [ $\left.{ }^{3}\right]$ позволяет определить транс-ориентацию заместителей в 4-метил- $\alpha$ иононе.

В следующих двух фракциях $\mathrm{C}_{14} \mathrm{H}_{22} \mathrm{O}$ аналопичные рассуждения указывают на транс- (элюируется первым) и циис-изомеры $\alpha$-ирона. В циис$\alpha$-ироне заместители при C-1 и С-5 должны иметь $e^{\prime} e$-ориентацию. В транс- $\alpha$-изомере заместитель при С-1 ориентирован псевдоаксиально, а при С-5 - экваториально. Химические сдвиги изомеров $\alpha$-ирона соответствуют этому предположению. Аксиальная метильная группа при С-6 имеет более сильные стерические взаимодействия с вицинальными заместителями в цис-изомере, по сравнению с транс-изомером. Соответственно, в цис-изомере аксиальная метильная группа при С-6 сдвинута на 5,3 м. д. в более высокое поле, по сравнению с транс-изомером.

Последний выделенный изомер $\mathrm{C}_{14} \mathrm{H}_{22} \mathrm{O}$ по химическим сдвигам должен быть гомологом $\beta$-ионона, и его химические сдвиги соответствуют предполагаемому $\beta$-ирону.

\section{Обсуждение результатов}

Проведенная работа позволила идентифицировать пять компонентов синтетического ирона, содержание которых составляло от 98,1 до 99,3\% от состава продукта синтеза (табл. 1,2 ; рисунок). Три компонента из пяти являются изомерами ирона (транс- $\alpha$-ирон, цис- $\alpha$-ирон и $\beta$-ирон), их синтезируют на основе 6-метилгеранилхлорида. Последний получают реакцией теломеризации 2,3-диметил-1-хлоро-2-бутена и изопрена [7]. На следующем этапе из 6-метилгеранилхлорида синтезируют (реакция Соммлета) 6-метилцитрал $\left[{ }^{8,9}\right]$ и, конденсируя его с ацетоном, получают псевдоирон. На последнем этапе циклизируют его с $\mathrm{BF}_{3}$ и получают ирон $\left[{ }^{10}\right]$.

$\alpha$-Ионон образуется при приведенных реакциях из геранилхлорида. Образование последнего связано с тем, что при реакции теломеризации между 2,3-диметил-1-хлоро-2-бутеном и изопреном в небольших масштабах происходит и дегидрохлорирование 2,3-диметил-1-хлоро-2-бутена. За счет освобождающегося при этом хлористого водорода образуется изопренгидрохлорид, который при реакции теломеризации с изопреном дает геранилхлорид.

транс-4-Метил- $\alpha$-ионон 4 (2,4,6,6-тетраметилцикло-2-гексенил) 3 -бутен2 -он синтезируется при приведенных реакциях из 5-метилгеранилхлорида. Последний образуется за счет 2-метилпентадиена, содержащегося в диметилбутадиене, при реакции его хлорида с изопреном.

Неидентифицированными компонентами синтетического ирона (рисунок) являются, вероятно, $\alpha$-1,2,6,6-тетраметил-, $\alpha-1,2,5,6,6$-пентаметил- и $\beta-2,4,6,6$-тетраметилциклогексенилбутеноны. Образование последних связано с синтезом 2-метилгеранилхлорида и 2,6-диметилгеранилхлорида. Кроме названных, вероятно присутствие и $\beta$-ионона. 


\section{Л И Т Е Р А Т Р А}

1. Li p pmaa, E., Pehk, T., P a st, J. Carbon-13 double resonance absorption spectra of strained molecules. - ENSV TA Toim., Füüs. Matem., 1967, k. 16, nr. 3, lk. 345-356.

2. J a utelat, M., Grutzner, J. B., Roberts, J. D. Natural-abundance ${ }^{13} \mathrm{C}$ nuclear magnetic resonance spectra of terpenes and carotenes. - Proc. Nat., Acad. Sci. U.S., 1970, v. 65, p. 288-292.

3. Пехк Т., Кооскора Х., Липпма а Э., Лысенков В. И., Бардышев И. И. Химические сдвиги ядер ${ }^{13} \mathrm{C}$ алкилциклогексенов. - Изв. АН БССР, Сер. хим., 1976, № 2, с. $27-32$.

4. Stothers, J. B. Carbon-13 NMR spectroscopy. New York, Academic Press, 1972, p. 436.

5. Row a n, R., Sykes, B. D. A carbon-13 nuclear magnetic resonance study of the visual chromophores and model compounds. - J. Amer. Chem. Soc., 1974, v. $96(22)$, p. $7000-7007$.

6. Engelh a rdt, G., J a nke, J., Mäg i, M., P ehk, T., Lip pmaa, E. Über die ${ }^{1} \mathrm{H}-,{ }^{15} \mathrm{C}$ - und ${ }^{29} \mathrm{Si}-\mathrm{NMR}$ chemischen Verschiebungen einiger linearer verzweigter und cyclischer Methylsíloxanverbindungen. - J. Organometallic Chemistry, 1971, v. 28, p. 293-300.

7. Л э э т с К. В. Авт. свид. № $105428,1955$.

8. Лебедев И. М., Фабричный Б. П., Черняк Н. В. Авт. свид. № 95174 , 1951.

9. Angya l, S. J., Penman, D. R., Warwick, G. P. The Sommelet reaction. Part IV. The preparation of aliphatic aldehydes. - J. Chem. Soc., 1953, N 6, p. $1737-1739$.

10. Белов В. Н., Да ев Н. А., К устов а С. О., Л ээтс К. В., Поддубная С. С., Скворцова Н. И., Шепельников Е. И., Шумейко А. К. Новый синтез ирона. - ЖОрХ, 1957, т. 27, № 5, с. 1384-1389.

Ннститут химии

Академии наук Эстонской ССР

Поступила в редакцию 24/XI 1977

T. SAKS, T. PEHK, H. RANG, A. IVANOV

\section{TELOMERISATSIOONIREAKTSIOONI TEEL SUNTEESITUD IROONI KOOSTIS}

Tehnoloogilisel seadmel telomerisatsioonireaktsiooni teel saadud 6-metüülgeranüülkloriidist sünteesitud iroon lahutati komponentideks preparatiivse gaasikromatograafia meetodil ning komponendid identifitseeriti massispektrite ja tuumamagnetresonantsspektroskoopia $\left({ }^{13} \mathrm{C}\right)$ abil. Peamised irooni komponendid on $\alpha$-jonoon, trans-4-metüül$-\alpha$-jonoon, trans- $\alpha$-iroon, cis- $\alpha$-iroon ja $\beta$-iroon; nad moodustavad $98,1-99,3 \%$ kogu irooni koostisest.

T. SAKS, T. PEHK, H. RANG, A. IVANOV

\section{THE COMPOSITION OF IRON SYNTHESIZED BY TELOMERIZATION REACTION}

The components of iron synthesized from 6-methyl geranyl chloride were separated by preparative gas chromatography. The components obtained were identified by their mass spectra and NMR-spectra $\left({ }^{13} \mathrm{C}\right)$.

It was proved that synthetic iron contains $\alpha$-ionon, trans-4-methyl- $\alpha$-ionon, trans$-\alpha$-iron, cis- $\alpha$-iron and $\beta$-iron. The amounts of these components in iron reaches $98.1-99.3$ per cent.

Syntheses of identified components are described. 